\title{
DISCOURSES ON BODY POSITIVITY: A FLUID BODY IMAGE CONCEPT BASED ON THE CASE STUDY OF JENNA KUTCHER INSTAGRAM ACCOUNT
}

\author{
Laura Pollaccia $^{1}$, Toms Kreicbergs ${ }^{2}$, Ieva Andersone ${ }^{3}$ \\ Department of Innovation and Business Management, Faculty of Engineering Economics and Management, \\ Riga Technical university, 6 Kalnciema street, Room 406, LV-1048, Riga, Latvia \\ E-mails: ${ }^{1}$ laura.pollaccia@gmail.com; ${ }^{2}$ toms.kreicbergs@rtu.lv; \\ ${ }^{3}$ ieva.andersone@rtu.lv(correspondingauthor)
}

Received 05 April 2020; accepted 07 May 2020

\begin{abstract}
The purpose of this research was to understand the concept of body positivity and changes in body image ideals. Authors analyzed how Jenna Kutcher, an Instagram influencer, was able to carry on the ideal of body positivity. Body positivity is a concept that shows support and appreciation towards all body types without discrimination on size or aesthetical appearance. This research focused mainly on the topic on changes in body image ideals, and the discourses related to them, that emerged in Jenna's posts and in her comments. The research was built on the literature review on body image and explored the importance of self-acceptance and self-satisfaction when considering the sense of attractiveness in individuals. Comments and posts were collected, coded an analyzed in accordance with a qualitative method of analysis. The research discussed how Jenna Kutcher was able to partially positively influence her audience through the use of the narratives in her pictures and the development of discourses around the body.
\end{abstract}

Keywords: body positivity, discourse, women's body image.

JEL Classification: M31.

\section{Introduction}

In this research authors decided to focus in understanding how an Instagram user such as Jenna Kutcher, who was given the role of influencer by the Instagram community, could help in the development of discourses and narratives around the body image. Therefore, the research questions were:

- How did Jenna Kutcher influence her followers on Instagram so that they would become more "body positive" or appreciative of all body types without discrimination to different sizes?

- What kind of discourses or cultural phenomena contributed to her goal as an influencer?

The research questions were asked as to understand how influencers can develop new discourses through the help on narratives in their pictures on Instagram. Although it must be said that the results of this study were specifically focused on the case study of Jenna Kutcher's Instagram and therefore cannot be generalized as might differ if studying other Instagram influencers. Nevertheless, the study provided new insights on possible discourses created around the concept of body positivity. The method was chosen based on the fact that knowledge created through discourse practices, according to Fairclough, "either contributes to reproduce society or transform society" (Fairclough, Discourse and social change, 1992, p. 65). Nowadays, thanks to social media, social interactions and social communication have developed- in fact, the type of communication among people does not just happened on a face-to-face basis, nowadays happens on screen-to-screen basis, too. People have a tendency to interact with other individuals through their technologies, too. What is interesting it how the event of the internet allowed a change in the way discourses are embedded in social practices. That is why Netnogaphy was used, more as a collection tool, due to the nature of the data. In addition, because the paper focused on discourses and language and the value of a critical discourse analysis lies in the fact it puts emphasis on language (Hart, 2010). The research in fact was based on understanding how the transformation of body image ideologies, through the help of Jenna Kutcher's influence on Instagram, was possible. From a Social Science perspective, authors assumed that we as humans feel the need to interpret our lives through a story or a so-called narrative that others can read and understand based on their specific lived context. As such, "we are a 
product of the stories that are told about us and the stories we tell for and about ourselves" (Goddard $\&$ Carey, 2017, p. 3). This was the part relevant to our research as discourses focus con communications and all the narratives that are used or generated in within such communications. It was important to understand how discourses could be formed and how they could be relevant to the creation of discourse communities focused on Instagram, where users communicate through writing texts to accompany their pictures.

The concept of body positivity has not yet been fully assessed by scholars, In fact, the whole purpose of the study was to understand the concept of "Body positivity" that was carried out by the influencer Jenna Kutcher. Body positivity, however, according to nonacademic articles (Dalessandro, 2016), overall followed the concept of appreciation of all body types in contrast to following any social standards on body image Therefore, it could be said that the topic of body positivity had been addressed indirectly through the topic of body image. Nowadays the ideal body image is represented by the "thin-ideal" which saw women as attractive if pertaining to a certain size group. However, authors considered important to understand how body image changed in America (where Jenna Kutcher is from) from the post WWII scenario. In fact, reviewing the literature it emerged that after WWII period and the advent of social movements such as feminism, a radical change in the portrayal of women and influenced their body image took place. In accordance with MacCallum and Widdows (2018), the negative view of body image is overall correlated the phycological wellbeing of individuals: "relating not just to appearance-changing behaviours such as dysfunctional eating behaviours, but also to general emotional difficulties such as distress and depression" (MacCallum \& Widdows, 2018, p. 236). That is how, I was able to link it to the ideal of "body positivity" which shows positive support and appreciation towards all body types without discrimination on size.

\section{Discourses theory and their influence on social practices}

"The term 'discourse' comes from Latin 'discursus', meaning 'to run to and fro" (Goddard \& Carey, 2017, p. 1). In all the varied uses of the term, both in everyday contexts and in more specialist academic fields, there is a commonly shared concept of discourses as expressions of ideas that are put out into the world and that "'run to and fro' "in one form or other" (Goddard \& Carey, 2017, p. 1). From a Social Science perspective, authors would assume that we as humans feel the need to interpret our lives through a story or a so-called narrative that others can read and understand based on their specific lived context.

Social media, especially Instagram (as it is the main focus of this article), are very popular: in 2019 , it is estimated that there will be around 2.77 billion social network users around the globe (https://www.statista.com, 2018). When considering discourses, Instagram is, in authors opinion a very interesting tool because it gives people the opportunity to interact openly with other users, often without any filters beside those which must be followed according to the terms and conditions of usage of the app. Instagram allows users to generate texts under pictures or on the pictures, or video content. This could be a new discourse that, as mentioned above, Goddard and Carey (2017) defined as expressions of ideas that are put out into the world and that 'run to and fro' in one form or other. Users, through the usage of hashtags can create connection from their posts to other public posts, which basically creates a cluster, and proceed into crating patterns and what could be called as a "discourse community" (Tiidenberg, 2017, p. 10). The use of hashtags makes it easier to find grouped content and as Tiidenberg (2017) stated, this may be done for a sense of community, for making connections, or as aspirational (Tiidenberg, 2017, p. 70). Communities as such seem to share certain characteristics beside the language which is employed to communicate information and spread knowledge. In this article authors focused on the women and also few men who follow Jenna Kutcher on Instagram and how iscourses emphasize body image's ideology creation.

\section{The role of feminism and beauty image: women's freedom of choice over their bodies}

From a strong patriarchal society in the 60 s, which was very influential on dictating which was the right body image that women needed to pursue, emerged another strong influential group: feminists. Feminists decided that women should have a saying, not only on their careers and lives but also on body image and ideals of beauty. Women wanted to be freed from the perfect picture that portrayed women as objects and especially as sexual objects. According to Scott (2005, pp. 320-322), even if the feminist movements all 
wished the best for women, it caused different feminist groups to develop political differences but nevertheless kept their common "desire to control the appearance of others" (Scott, 2005, p. 320). Feminists have tried to promote a natural body image which was undressed of all the fashionable standards that the fashion industry and now social media have tried to feed to women. What is interesting is how "it seems clear that women are quite capable of critiquing the current standards for beauty and the images portraying these standards, but they continue to feel bound by them and motivated to attain them", (Calogero et al., 2007, pp. 285-286). Nowadays, "many women continue to engage in beauty practices and perceive being 'beautiful' as empowering; this is despite the widely held view that female beauty ideals are oppressive and contribute to the objectification, devaluation, and subordination of women" (Calogero et al., pp. 285-286). The ideals of right and wrong around female beauty, and consequentially on body image, has been dictated by men and then consequentially by influential women. In addition to the evolution of feminisms, there is another theoretical ideology that influenced body image and that is the ideology of body image often created through social media through the processes of objectification (Fox \& Vendemia, 2016, p. 593). Such ideology explained how women take an outsider's perspective of themselves and critically evaluate their worth based on social standards (Fox \& Vendemia, 2016, p. 593). From a theoretical perspective, Kapidzic and Martins (2015, p. 281) also stated how mass media content often reinforces the value of physical attractiveness, however, from the analysis of the comments it emerged that it is true not only for physical attractiveness but also for self-worth. To make it very, very simple: women have been influenced by different ideologies that then they make their own and which contributed to creating certain social practices over body image. Their own understanding of their level of attractiveness and their comparison of such levels, became a practices through the influence partially through feminism, and social media pressure. Women end up comparing themselves as they perceive that they must attain certain standards to be considered worth of being part of the actual society or the social-media society.

\section{Importance of physical attractiveness}

According to E. Henderson-King and D. Henderson-King (1997, p. 1) "social psychology has documented the importance of physical attractiveness in people's social judgments (e.g., Dion, Berscheid, \& Walster, 1972; Hatfield \& Sprecher, 1986)". Social rewards are clearly influenced by individuals' physical attractiveness. Making salient the fact that negative social judgments are passed on those who are evaluated as unattractive could heighten people's awareness of the importance of physical appearance. It came to my attention that the factor of judging physical attractiveness gives a lot of importance to physical appearance and thus influences one's perception of one's body image so that it could fit in a judgmental environment.

"Bodies exist within social and cultural contexts, and hence are also constructed through sociocultural practices and discourses" (Fredrickson \& Roberts, 1997, p. 174). Therefore, the way the body is represented has a specific meaning that can be interpret in different ways. Photos typically focus on users' physical appearance, which may compound existing sociocultural pressures about body image (Fox \& Vendemia, 2016, p. 593). A review of the literature on the portrayal of the appearance of men and women in mainstream media highlight three prominent manners in which this is achieved: focusing on a person's body (Lambiase \& Reichert, 2006), portraying characters wearing revealing clothing (Reichert \& Carpenter, 2004), and showing characters posing with an averted gaze (Bell \& Milic, 2002), (Kapidzic \& Martins, 2015, p. 281). What interested authors was how to understand how the perfect body image was fed to the audience which then consciously selected it as its own truth. This behavior was explained through objectification theory.

\section{Objectification and comparison of attractiveness}

Objectification theory states that: "women are socialized to take an outsider's perspective of themselves and critically evaluate their worth based on societal standards, such as prioritizing one's appearance" (Kapidzic \& Martins, 2015, p. 281). This theory was relevant for this research because it highlighted how women critically focused on their exterior appearance and evaluate their worth based on standards which were developed in society therefore allowing external factors to influence their ideal of body image. Selfobjectification was seen as a negative concept as it "has been tied to several detrimental outcomes, including depression, body shame, and disordered 
eating" (Kapidzic \& Martins, 2015, p. 281). In addition, "objectifying messages about appearance could prime women to focus more on their appearance" (Tylka \& Sabik, 2010, p. 18). Therefore, the focus on appearance brought women to compare themselves to others in order to understand how attractive they were and if they were up to the social standards: "at a psychological level, perhaps the most profound effect of objectifying treatment is that it coaxes girls and women to adopt a peculiar view of self" (Fredrickson \& Roberts, 1997, p. 178). In this research authors wished to understand if the positive message could in any ways influence the physical perspective of the self and which tools could be adopted to improve those changes. With the use of social media, in this case of Instagram, another phenomenon arose: internalization. "It refers to a person's incorporation of the ideals presented in the media as personal standards" (Trekels et al., 2017, p. 469). It corresponds to basically making someone else's ideology, which is presented on the media, as if it was our own. "The message that women's worth is equated with their bodies is often internalized by women as well as their significant others, who then evaluate the worth of their female partners, daughters, mothers, sisters, and female friends by the extent to which they resemble this image (i.e., appearance feedback), (Tylka \& Sabik, 2010, p. 19). This theory was very relevant for our reserch to understand how this process of creation or development of different ideals on the body works and the results showed indeed that often the process of creation happened through social comparison and had an impact on self-esteem. "Social comparison theory, as first put forward by Festinger, postulates that humans have a desire to self-evaluate, and that where no objective measurement of our attributes is possible, as with appearance, we do so through comparison with others" (MacCallum \& Widdows, 2018, p. 239). "The internalization of appearance ideals has been thoroughly studied and validated as a mediator in the association between media exposure and body image disturbances" (Thompson \& Stice, 2001, p. 181). "Berg, Roehrig, Guarda, and Heinberg (2004) argued that these standards become guiding principles that affect cognitions and behaviors to approximate the ideals (p. 294)", (cited in Thompson \& Stice, 2001, p. 181). Therefore, authors would say that social media works as a tool that through repetition of similar visual stimuli (in the case of Instagram: pictures, texts and hashtags) was able to influence and therefore reinforce certain beliefs which then would partially influence the final personal ideology on body image of their audience. The use of images on social media are influential over the spreading of those ideals and social standards of beauty: "Extensive research supports this, with exposure to visual mass media depicting idealised bodies being associated with body image disturbance in both experimental and correlational studies" (MacCallum \& Widdows, 2018, p. 236). In accordance with MacCallum \& Widdows (2018), the negative view of body image is overall correlated the phycological wellbeing of individuals: "relating not just to appearancechanging behaviours such as dysfunctional eating behaviours, but also to general emotional difficulties such as distress and depression" (MacCallum \& Widdows, 2018, p. 236). The overall dissatisfaction is influenced by digital alteration. Digital alteration is commonly used nowadays, and it was important to mention its relevance in this research as often, Jenna Kutcher, referred to it and its bad influence on women's self-worth. This was due to the tendency of women to follow the unattainable standards that the modified pictures presented. The images which are digitally modified generated an idealized and unreal representation of the body which then "set higher expectations of what is normal, good enough, or perfect" (MacCallum \& Widdows, 2018, p. 236).

\section{Methodology}

The focus of research was on understanding how Jenna Kutcher influenced her followers on Instagram so that they would become more "body positive" or appreciative of all body types without discrimination to different sizes and what kind of discourses or cultural phenomena contributed to her goal as an influencer. Authors opted to analyze this topic through qualitative research due to the fact that it allows to understand the meaning of the world around us humans and gives a way to properly interpret it. As a method for data collection we decided to use primary data collection of comments and posts on Instagram because that reduce the error that might come from analyzing secondary data. In order to collect the data, authors used the method called Netnography. Netnography uses things such as posts, comments which are available online on different platform as data. Netnography it's about following conversations, finding online places of interaction, capturing that data in some way, analyzing it, looking for commonalities in it (Kozinets, 2011, p. 1), 
however the purpose of Netnogaphy in our research was as only a collection data method because the data was online. The collected data corresponds to six different posts on Jenna Kutcher's (2018) Instagram and 500 comments from each post using https://exportcomments.com/ as the tool to gather the data. The posts were collected on a chronological order and were divided in three different phases: pre-viral, viral and post-viral phase. The best option, when analyzing language, is Critical Discourse Analysis (CDA). Critical Discourse Analysis is a research enterprise which critically analyses the relationship between language and society (Hart, 2010, p. 1). The value of a critical discourse analysis lies, in the fact it puts emphasis on language. Instagram gives people the chance to post content which can consist of verbal content (a video) beside the common figurative content (a picture). A discourse analysis would help in understanding the threads and patterns and the discourses the community that follows Jenna Kutcher shares. Authors adapted seven steps from the book "Systematic Coding in Qualitative Research" by Anselm L. Strauss (1990, p. 53), in order to code the material and reach the final discourses.

\section{Results and discussion}

The whole research focused in understanding how body image ideologies are expressed through Jenna's Instagram and how they would influence her followers and help in the creation of a new ideology around their perception of body image and if, overall this process was actually possible. What emerged from the analysis were three main discourses around the body image: The first discourse produced a discussion over the definition of the "real body" theoretically speaking, objectification theory (Fox \& Vendemia, 2016, p. 593) affirmed how the creation of body image is done through an outsider's perspective of the body. Therefore the summary was that individuals choose, and often accept as their own, a mainstream ideal of body image which is given by social standards. After the analysis it became evident how this process of destruction and recreation of the self-body image was quite hard to perform but possible through the help of Jenna's new definition of the body. Jenna stated that a normal body is a body with flaws and without filters, so all body types would fit in her definition without exclusion of different sizes. Following this theme, it also emerged how the supporting followers would, through the process of internalizing
(Trekels et al., 2017, p. 469), strive to make Jenna's ideals as their own. From this process emerged and interesting consequence related to self-worth. However, their intent was not to follow their partners' ideal of beauty, but to follow the concept of "self-acceptance" of all flaws. The idea was that as their partners would love them for who they were, so they also could find enough selfworth to love themselves without caring about an external approval. The second discourse focused on body positivity and the importance of selfacceptance of the body through positive reinforcement. According to Kapidzic and Martins (2015, p. 281), media portrayals teach young men and women that they will be judged based on their appearance (Fredrickson \& Roberts, 1997) and often conflate personal success with physical features rather than personality (Aubrey, 2006). However, in the case of self-worth and acceptance, this was partially confuted due to the importance given by the followers to a personality trait rather than the physical ones. Jenna's messages discuss self-acceptance in positive terms and the followers responded to this in a very positive way: often they would call Jenna as an inspiration and expressed how they try to apply her ideology of selfacceptance and self-love. The last discourse was the most negative one: body-shaming. According to the literature review, individuals with low selfesteem tend to focus on negative evaluations, interpret evaluative information in a manner which reinforces their negative self-evaluations, and favor protecting themselves against loss of face (Baumeister, 1993; Tice, 1992), (cited in KanatMaymon et al., 2018, p. 228). This tendency could also be found in these data. Mainstream ideaology support thinner bodies: according to the litterature review, current western societies are inordinately emphasizing thinness as an ideal for female beauty, and women receive more social pressures to be beautiful than ever before (Basow et al., 2007; Schwartz et al., 1999), (cited in Lee, 2013, p. 1). Thus women are pressured to look thin in order to be consider as physically attractive by societal standards. Appearance is then considered very important: "it serves as a powerful stimulus for social evaluation as well as self-evaluation (Cash et al., 1988; Franzoi \& Herzog, 1987; Lerner, 1987)", (cited in Rosenblum \& Lewis, 1999, p. 51). Social evaluation and self-evaluation brings to dissatisfaction since women then feel to not fit in the standard of attractiveness. Presumably, the more pervasive media imagery is, the more women feel that they must meet these unattainable standards and the less positive they feel about their 
bodies (E. Henderson-King \& D. Henderson-King, 1997, p. 399). This dissatisfaction and unappreciation of body image generated a tread of comments which were against different body types, especially the thin ones in contraposition to the curvier ones, which were attacked and discriminated. What emerged from the theoretical perspective was that the ideology of body image was often created through social media through the processes of objectification (Fox \& Vendemia, 2016, p. 593) that explained how women take an outsider's perspective of themselves and critically evaluate their worth based on social standards (Fox \& Vendemia, 2016, p. 593).

From a theoretical perspective, Kapidzic and Martins (2015, p. 281) also stated how mass media content often reinforces the value of physical attractiveness, however, from the analysis of the comments it emerged that it is true not only for physical attractiveness but also for self-worth. In fact, after analyzing the comments and the discourse that emerged around the "real body", self-worth was as important and influenced by social media as physical attractiveness usually has been studied to be. After analyzing the comments these sequences of literature revealed to be true. Jenna invited the followers to write down their thoughts and opinions on her pictures or her written content: this action influenced the process of internalization. The action of incorporating ideals which are presented in the media is defined as internalization (Trekels et al., p. 469). It was relevant to consider internalization theory as the responses that majority of her followers gave were tuned with her thoughts. In fact, there was a link from the discourse generated from her captions and the reactions to her posts it in her comments. From the analysis of her posts it emerged how the definition of normal body for Jenna corresponded with a body which goes against the mainstream culture of thin body which Jenna called "thinspiration" while Thompson and Stice (2001, p. 181) defined it as thin-ideal. Therefore, the new definition of real body became a body which is accepted within any imperfection that society might uncovers or tries to cover with filters. What was contradictory for me was the concept of "real" which was put side by side with the concept of "imperfect". What I thought was that if all body types are accepted then there would be no need to use words as "flawed" or "imperfect" as we all would be perfect. As Sandra Bartky (1990) promoted a revolutionary new aesthetic of the body which perceives a range of body shapes to be acceptable, and which challenges traditional conception of "slim as beautiful" (Grogan, 1999, p. 115), Jenna worked through her Instagram to accomplish the same. One of the most interesting part was that from the whole discussion around flaws a new tread appeared: the discourse of selfacceptance as the key to self-love. What emerged was how the discourse of acceptance of flaws was built on a construct of self-worth linked to the ideal of physical attractiveness: "given that many women learn that their worth is equivalent to their appearance, another manifestation of this appearance-focus could be women's decreased self-worth if they do not match up with societal ideals" (Tylka \& Sabik, 2010, p. 18). In details, analyzing the comments of the followers, it appeared that feeling attractive was directly related to their self-worth but not vice versa. So, to explain further: they considered that their ideal of physical attractiveness increased with their self-worth, but their self-worth did not particularly increase with the reaching of those social standards of attractiveness. It was as if the societal standards were always changing, little by little, to higher standards and women could not catch up with it. It must be said again that when talking about social standards of attractiveness they focused on the concept of thin women as the ideal body image. According to the literature review, self-esteem is a central aspect of the subjective experience and quality of life (Wolfe \& Croker, 2001, p. 593): authors would argue that people with a higher selfworth tend to have a more positive attitude. The literature review reported that this phenomenon is powerfully related to variables that influence the affective tone of one's daily experience, with highself-esteem people reporting more positive affect (Brockner et al., 1983; Pelham \& Swann, 1989), (cited in Wolfe \& Croker, 2001, p. 593). From the analysis we understood that self-acceptance was capable of increasing self-esteem and therefore the followers felt more attractive because they accepted themselves. What authors notices was an interesting phenomenon: Jenna repeated herself in stating the importance of accepting "ALL bodies" however, there were some relevant comments which went against this message. In the end, I noticed how two different groups of followers formed: the first one was composed by members who felt they were "curvy" and discriminated by the fat-shaming ideal and opted to attack and discriminate their opposite (= skinnier women); while the second group was composed by women who felt the need to express how they felt discriminated because considered "too skinny". On one side curvier women felt discrimination for 
being "fat", on the other side, skinnier women felt discriminated for being "skinny". Authors also noticed how, due to the mainstream ideal being that skinny was a model to follow, skinnier women felt their voices were not heard because they pertained to the "perfect size" and therefore it raised the issue on how, on paper, they were considered perfect and therefore immune to low self-worth or self-appreciation. However, the discourse around shaming the body, howed how all women are exposed to low-self-esteem and insecurities, no matter their sizes. According to the literature review, "individuals with low self-esteem tend to focus on negative evaluations, interpret evaluative information in a manner which reinforces their negative self-evaluations, and favor protecting themselves against loss of face (Baumeister, 1993; Tice, 1992)", (cited in KanatMaymon et al., 2018, p. 228). This showed to be true. Mainstream ideaology supported thinner bodies: according to this concept, current western societies are inordinately emphasizing thinness as an ideal for female beauty, and women receive more social pressures to be beautiful than ever before (Basow et al., 2007; Schwartz et al., 1999), (cited in Lee, 2013, p. 1). Presumably, the more pervasive is media imagery, the more women feel that they must meet these unattainable standards and the less positive they feel about their bodies (E. Henderson-King \& D. Henderson-King, 1997, p. 399). This dissatisfaction and unappreciation of self-body image generated a tread of comments which were against different body types, especially the thin ones in contraposition to the curvier ones, which were attacked and discriminated. However, as stated before, this discourse went against Jenna's self-acceptance ideology: she openly expressed her disfavor toward body-shaming of any type. The fact that a body-shaming discourse survived through her positive self-accepting ideology, showed how her message was not able to spread. My assumption was that a different ideology was too emotionally embedded in the life of the followers; for example, curvier followers felt that they had been shamed by the mainstream ideology that portrayed thin bodies as the best bodies, therefore, now they felt the need to use Jenna as their ambassador in a way that Jenna did not approve of. They will use her being a curvier and popular woman as a defense for their shaming smaller sizes. On the other hand, smaller sizes themselves have reported how shaming was also inflicted to them and how harder it was for them to be understood in relation to the discourse of selfworth. The followers who pertained to the category of smaller sizes argued that their freedom to discuss self-worth and acceptance of their bodies was a taboo due to the shaming they received from bigger sizes. It was interesting to see how all sizes felt discriminated in some way and however Jenna explicitly invited everybody to stop the shaming, this phenomenon still appeared.

\section{Conclusions}

Whole research authors focused in understanding how body image ideologies expressed through Jenna's Instagram would influence her followers and help in the creation of new discourses around their perception of body image. Jenna's message was spread through a strategic use of the narrative in her pictures combined with the discourses in her Instagram captions. Jenna helped in developing a new concept which was defined on Instagram as "body positivity", namely acceptance of all body types and shapes. This concept was supported by the discourses on the real body and spread thanks to the effects of objectification theory: as individuals accepted a main stream ideal of body image which was presented by social standards, they also were able to switch and adopt the definition given by Jenna. Statistically speaking, her followers went up of 147k Instagram followers in the week after her Post 3 went viral, which showed how her posts were positively accepted by the Instagram community. Jenna stated that a normal body was a body with flaws and without filters, so all body types would fit in her definition including different body types and sizes. One of her goal was also to motivate women into accepting themselves and loving themselves without the need to retouch or conform to societal standards. However, Jenna, supportive of the discourse of accepting everybody, proved that true liberation for women comes from nothing less than acceptance. Acceptance must start from in within and it happened through the increasing of selfworth. Self-worth was increased through using Jenna as an inspiration and through the repetition of positive affirmations. However, self-worth proved to be something highly influenced by internal sources more than by external sources. Therefore, Jenna was as an input for these women and helped them to generate a more positive inner dialogue through her discourses on body image. In addition, an interesting negative discourse developed in contraposition to the positive spreading of Jenna's message. The concept of freedom for women, according to Jenna excluded the ideal of shaming or judging based on physical appearance. 
The analysis proved that shaming was based on lack of self-love: the person without self-love was not free because still attached to those societal ideals of what was right and wrong when talking about appearance.

Women and men in this case, decided to attack any body size which did not correspond to their ideals of body image. In conclusion, it was possible for Jenna to influence her followers and to create new discourses around the body image strategically using only her Instagram pictures and captions. However, she was not in control of all the discourses that emerged (for example, the bodyshaming discourse), thus authors considered her influence partial.

There were a number of limitations to this research. On a methodological level, the almost lack of tools needed to extract comments for free from platforms such as Instagram caused the whole sample of comments to be restricted. This factor partially limited the selection of comments. Also, discourses have an everchanging nature as they influence and are influenced by actions and language, therefore can change over time. However, this research focused on analyzing a portion of the comments in Jenna's Instagram and therefore, as stated in the introduction, this research was designed on the case of Jenna Kutcher's Instagram and thus it might not apply to other research on discourses on Instagram. However, this research can still be used as an inspiration for future research as it gave an insight on how the concept of body image is always changing.

\section{References}

Calogero, R. M., Boroughs, M., \& Thompson, J. K. (2007). The impact of western beauty ideals on the lives of women: a sociocultural perspective. In V. Swami, \& A. Furnham (Eds.), The body beautiful (pp. 259-298). Palgrave Macmillan. https://doi.org/10.1057/9780230596887_13

Dalessandro, A. (2016, June 19). 15 definitions of body positivity straight from influencers \& activists. https://www.bustle.com/articles/165804-15definitions-of-bodypositivity-straight-frominfluencers-activists

Fairclough, N. (1992). Discourse and social change. Polity Press. https://doi.org/10.4324/9780203697078

Fairclough, N. (2003). Analysing discouse. Routledge.

Fox, J., \& Vendemia, M. A. (2016). Selective selfpresentation and social comparison through photographs on social networking sites.
CyberPsychology, Behavior, and Social Networking, 19(10), 593-600. https://doi.org/10.1089/cyber.2016.0248

Fredrickson, B. L., \& Roberts, T. A. (1997). Objectification theory: Toward understanding women's lived experiences and mental health risks. Psychology of Women Quarterly, 21, 173-206. https://doi.org/10.1111/j.1471-6402.1997.tb00108.x

Goddard, A., \& Carey, N. (2017). Discourse: the basics. Routledge.

Grogan, S. (1999). Body image. Routledge.

Hart, C. (2010). Critical discourse analysis: critical discourse analysis and cognitive science. Palgrave Macmillan. https://doi.org/10.1057/9780230299009

Henderson-King, E., \& Henderson-King, D. (1997). Media effects on women's body esteem: social and individual difference factors. Journal of Applied Social Psychology, 27(5), 399-417.

https://doi.org/10.1111/j.1559-1816.1997.tb00638.x

https://www.statista.com. (2018).

https://www.statista.com/statistics/278414/number of-worldwide-social-network-users/instagram.com

Kanat-Maymon, Y., Almog, L., Cohen, R., \& AmichaiHamburger, Y. (2018). Contingent self-worth and Facebook addiction. Computers in Human Behavior, 88, 227-235. https://doi.org/10.1016/j.chb.2018.07.011

Kapidzic, S., \& Martins, N. (2015). Mirroring the media: the relationship between media consumption, media internalization, and profile picture characteristics on Facebook. Journal of Broadcasting \& Electronic Media, 59(2), 278-297. https://doi.org/10.1080/08838151.2015.1029127

Kozinets, R. (2011). What is netnography? S. P. Ltd.

Kozinets, R. V. (2002). The field behind the screen: using netnography for marketing in online communities. Journal of Marketing Research, 39, 61-72. https://doi.org/10.1509/jmkr.39.1.61.18935

Kutcher, J. (2018). https://podcast.jennakutcher.com/

Lee, M. S. (2013). Women's body image throughout the adult life. Iowa State University.

MacCallum, F., \& Widdows, H. (2018). Altered images: understanding the influence of unrealistic images and beauty aspirations. Health Care Anal, 235245. https://doi.org/10.1007/s10728-016-0327-1

Rosenblum, G. D., \& Lewis, M. (1999). The relations among body image, physical attractiveness, and body mass in adolescence. Child Development, 70(1), 50-64. https://doi.org/10.1111/1467-8624.00005

Scott, L. M. (2005). Fresh lipstick: Redressing fashion and feminism. Palgrave Macmillan..

Strauss, A. L. (1990). Systematic coding in qualitative research. Bulletin de Methodologie Sociologique, 27, 52-62. https://doi.org/10.1177/075910639002700103 
Thompson, J. K., \& Stice, E. (2001). Thin-ideal internalization: mounting evidence for a new risk factor for body-imagedisturbance and eating pathology. Current Directions in Psychological Science, 10(5), 181-183. https://doi.org/10.1111/1467-8721.00144

Tiidenberg, K. (2017). Visibly ageing femininities: women's visual discourses of being over-40 and over50 on Instagram. Feminist Media Studies, 18(1), 61-76.

https://doi.org/10.1080/14680777.2018.1409988

Trekels, J., Vangeel, L., \& Eggermont, S. (2017). Media ideals and other-sex peer norms among Belgian early adolescents: equating self-worth with attractiveness. Journal of Children and Media, 11(4), 466-484.

https://doi.org/10.1080/17482798.2017.1348371

Tylka, T. L., \& Sabik, N. J. (2010). Integrating social comparison theory and self-esteem within objectification theory to predict women's disordered eating. Sex Roles, 63, 18-31. https://doi.org/10.1007/s11199-010-9785-3

Wolfe, C. T., \& Croker, J. (2001). Contingencies of self-worth. Psychological Review, 108(3), 593 623. https://doi.org/10.1037/0033-295X.108.3.593 